our review of the literature" or "so far as we know" are not enough. In our age of computerized search, it is not difficult to be sure.

Our reviewers should increase attention to matters of priority. That would prevent most of the controversy. Also, if a reader submits an appropriate documented challenge on such issues, the editor may find it proper to request that the author of a particular article clarify the matter or even issue an erratum.

Issues of priority are taunted by streaks of vanity, but they also represent milestones of an individual surgeon's career and are sometimes symbols of lifetime achievements. Claims to priority or even references to priority are factual statements. Our professional journals request that all facts presented should be true and accurate. Why should issues of priority be exceptions?

This-so far as I can tell-is the first such editorial in a surgical journal. I hope it transcends into history.

\section{The Editor Responds}

How could any editor not acknowledge the durable wisdom of Francis Robicsek, a genius surgeon whose intel- lectual breadth most of us can only contemplate in awe? But, is it really important who or what was "first" or is it more important who "scores?" The latter is something of which we can keep track. The great surgeon Henry Souttar was probably the first to do a successful mitral valvotomy. But, did his operation benefit patients during the 20 years that it took before Charles Bailey and Dwight Harken popularized the operations? The Editors of the Journal are interested in "who is on first," but mainly in retrospect, when contemporary events are examined through the eyes of the historian trying to create an impetus to thought or progress. Those firsts have earned their place in history. The "first" of today may, in fact, be at the leading edge of infamy absent the wisdom of history, that most perfect of judges. So, we are happy to publish great ideas and operations for which there is no apparent prior report (that, of course, would represent "duplicate publication"). We simply prefer not to allow authors to claim primacy. For the best of ideas and procedures, we will allow history to be the judge of who was "first" and who "scored."

Andrew Wechsler, MD 